\title{
Does metabolic health in overweight and obesity persist? - Individual variation and cardiovascular mortality over two decades
}

\author{
Akaal Kaur, Desmond G Johnston and lan F Godsland \\ Diabetes Endocrinology and Metabolic Medicine, Faculty of Medicine, Imperial College London, \\ St Mary's Campus, London, UK
}

\author{
Correspondence \\ should be addressed \\ to I F Godsland \\ Email \\ i.godsland@imperial.ac.uk
}

\begin{abstract}
Objective: Overweight and obese individuals may be metabolically healthy, but attention needs to be given to long-term persistence of this trait and any associated variation in cardiovascular risk.

Design: Cross-sectional and longitudinal variation in metabolic health and associated cardiovascular mortality were analysed in 1099 white European-origin normal-weight and overweight or obese males followed for 20 years. Methods: Definitions of metabolic health were based on LDL and HDL cholesterol, triglycerides, blood pressure, fasting glucose and cardiovascular risk. Insulin resistance (e.g. HOMA-IR) and sub-clinical inflammation (ESR and white blood cell count) were explored. Cardiovascular mortality risks and persistence of metabolic health status were evaluated.

Results: There were 87 cardiovascular deaths. Insulin resistance was increased in metabolically healthy overweight or obese participants (median HOMA-IR 2.63, $95 \% \mathrm{Cl}: 1.79-3.65, P<0.001$ ) relative to normal-weight participants (median HOMA-IR $1.67,95 \% \mathrm{Cl}: 1.08-2.67, P<0.001$ ) as was sub-clinical inflammation but metabolically healthy overweight or obese individuals were not at increased risk of cardiovascular mortality compared with the metabolically healthy normal-weight individuals (hazard ratio $1.13,95 \% \mathrm{Cl}: 0.34-3.72, P=0.8$ ). The proportions of initially metabolically healthy overweight or obese who remained metabolically healthy for visits 2,3 and 4 were 54,48 and $39 \%$ respectively, and for initially normal-weight individuals, 68,51 and $41 \%$. A lower proportion of metabolically healthy overweight or obese individuals remained metabolically healthy at visit 2 compared with normal-weight individuals $(P=0.007)$, but proportions converged thereafter.

Conclusions: Despite being insulin resistant and having greater sub-clinical inflammation, and despite instability in metabolic health status, metabolically healthy overweight or obese individuals were at no greater risk of cardiovascular mortality than their normal-weight equivalents.

European Journal of Endocrinology

(2016) 175, 133-143

\section{Introduction}

Overweight (OW) and obesity (OB) are associated with physiologic and metabolic disturbances that predispose towards the development of type 2 diabetes mellitus, cardiovascular disease (CVD) and cancer. In the 1980s, sub-groups of $\mathrm{OB}$ individuals were identified that appeared free of typical adiposity-related disturbances

(1), and it was suggested that some $\mathrm{OB}$ individuals might not be at increased risk (2). Subsequently, the concept of metabolically healthy (MH) obesity was adopted (3). Estimates of the prevalence of $\mathrm{MH}$ OB in Europe range between 2 and 19\% in men and 7 and $28 \%$ in women (4).
\end{abstract}


Problems consistently raised in commentaries on $\mathrm{MH}$ OW and $\mathrm{OB}$ have included the lack of an agreed definition of metabolic health and the fact that a continuum of variation in metabolic disturbance extends across all levels of adiposity $(5,6,7,8)$. Nevertheless, if a pragmatic definition of $\mathrm{MH}$ could be agreed, it might yet be used to identify OW or OB individuals who need not benefit from intensive weight loss. In a detailed review, Stefan et al. distinguished three types of investigation, differing according to whether MHO had been defined with reference to insulin sensitivity, cardiorespiratory fitness or a putative 'metabolic syndrome' (7). Measures of insulin sensitivity and cardiorespiratory fitness (and inflammatory markers, which have also been used to define $\mathrm{MH}$ ) are not routinely available. However, defining $\mathrm{MH}$ with reference to readily available risk factor measures does offer a practical tool with which low-risk OW or OB individuals might be identified.

In the present analysis, we explore data from the HDDRISC study, in which a broad range of risk factors was recorded in 1191 white European males, a substantial proportion of whom had repeated follow-up information recorded at 2-3-year intervals. Applying a definition of $\mathrm{MH}$ based on readily available risk factor measurements and their associated CVD mortality risks in the HDDRISC cohort, we test the following hypotheses: (i) $\mathrm{MH}$ overweight or obese (OWOB) individuals are at greater risk of CVD mortality than $\mathrm{MH}$ normal-weight (NW) individuals; (ii) $\mathrm{MH} \mathrm{OWOB} \mathrm{individuals} \mathrm{are} \mathrm{insulin}$ resistant and exhibit sub-clinical inflammation relative to MH NW individuals and (iii) $\mathrm{MH}$ in OWOB individuals is a persistent trait, sustained over long-term follow-up.

\section{Subjects and methods}

\section{Design}

The Heart Disease and Diabetes Risk Indicators in a Screened Cohort (HDDRISC) study began as a company health program to evaluate risk factors for CVD and diabetes. The study recruited 1191 white European males (age range $25-70$ years; BMI range $18.1-46.9 \mathrm{~kg} / \mathrm{m}^{2}$ ) who were generally healthy and either in employment or recently retired and data acquisition was between June 1971 and January 2000. Metabolic, clinical and laboratory measurements were recorded for each participant at their first visit, and for those continuing in the study, at subsequent follow-up visits every 2-3years. Ethics committee approval was obtained and each participant gave written, informed consent.

\section{Procedures}

Procedures have been described in detail previously (9). Briefly, participants were instructed to fast overnight and, beforeattendance at a metabolic day ward the next morning, refrain from drinking alcohol and smoking. Demographic data, including self-reported cigarette smoking $(0,<15$, $\geq 15$ cigarettes per day), alcohol consumption $(0,<28, \geq 28$ units per week) and exercise habits (none, nonaerobic, aerobic, with aerobic distinguished as 3 or more periods of $\geq 20$ min of exercise to breathlessness) and medical history were recorded. After $15 \mathrm{~min}$ in a semi-recumbent position, systolic and diastolic blood pressures (SBP and DBP respectively) were measured. Blood samples were taken from an indwelling cannula for laboratory measurements. A further sample was taken 5-10 min later for a second measurement of fasting plasma glucose and insulin (FPG and FPI). The majority of participants then underwent an oral glucose tolerance test (OGTT: 50\% dextrose solution at $1 \mathrm{~g}$ glucose $/ \mathrm{kg}$ body weight) and samples were taken to measure plasma glucose and insulin at 30, 60, 90, 120, 150 and $180 \mathrm{~min}$.

\section{Laboratory measurements}

Plasma glucose and insulin and serum triglycerides and total, HDL and LDL cholesterol concentrations were measured by the HDDRISC research group as described previously (9). Routine haematology and biochemistry measurements included white blood cell count (WBC) and erythrocyte sedimentation rate (ESR) as indices of subclinical inflammation and were undertaken either by the research group or the local chemical pathology laboratory. Between- and within-batch quality control was monitored by frozen, pooled plasma samples and commercially obtained lyophilised sera and by participation in relevant national quality assurance schemes with particular attention paid to long-term assay standardisation.

\section{Definition of metabolic health}

Clearly, increased BMI cannot be included as a criterion for $\mathrm{MH}$ in an analysis of $\mathrm{MH} \mathrm{OW}$ or $\mathrm{OB}$, and this extends to increased waist circumference which displays marked co-linearity with BMI (4) and has been excluded from the majority of definitions of $\mathrm{MH} \mathrm{OW}$ or $\mathrm{OB}(7,10,11$, 12). Other readily available criteria then include plasma lipid, lipoprotein and glucose concentrations and blood pressure. Five criteria are considered in the present analysis: LDL-C of $\geq 3.36 \mathrm{mmol} / \mathrm{L}$ or use or a statin and 
(with cut-offs defined according to metabolic syndrome criteria $(13,14)) \mathrm{TG} \geq 1.7 \mathrm{mmol} / \mathrm{L}$ or use of a fibrate, HDL-C $<1.03 \mathrm{mmol} / \mathrm{L}, \mathrm{SBP} \geq 130 \mathrm{mmHg}$ systolic or DBP $\geq 85 \mathrm{mmHg}$ or use of blood pressure-lowering agents and FPG $\geq 5.6 \mathrm{mmol} / \mathrm{L}$ or a diagnosis of diabetes mellitus and/or use of glucose-lowering agents. The question then arises, how many, if any, of the criteria may be allowed to be present before $\mathrm{MH}$ can be excluded? Previous studies of MHO employing similar criteria have allowed none $(4,12$, $15), \leq 1(10,11,16,17)$ or $\leq 2(18,19,20,21)$. In the present analysis, in the full dataset before exclusions (see below), each of the five risk factors was confirmed as a predictor of CVD and total mortality in univariate Cox proportional hazards models, unadjusted for any factors that might influence variation in risk factor levels. Participants were then distinguished according to whether they had $0,1,2,3,4$ or 5 risk factors and numbers of risk factors were entered as dummy variables in an unadjusted Cox model to determine at what level of risk factor number significant risk of CVD or total mortality would become apparent. Participants with fewer than that number were then identified as $\mathrm{MH}$ - 'metabolically healthy' - and those with that number or more as MUH - 'metabolically unhealthy'. We, therefore, 'calibrated' our criteria for $\mathrm{MH}$ against actual clinical risks they conferred in the HDDRISC cohort.

\section{Definition of overweight}

Preliminary analysis indicated that among obese (BMI $\geq 30.0 \mathrm{~kg} / \mathrm{m}^{2}$ ) participants, numbers were insufficient for a reliable evaluation of CVD mortality (12 CVD deaths among the 83 OB participants, with only 1 CVD death (5 deaths in total) among the $13 \mathrm{MH}$ OB participants). Therefore, OW and $\mathrm{OB}$ individuals were combined in a single group (OWOB). Rather than the conventional lower limit for OW of $25.0 \mathrm{~kg} / \mathrm{m}^{2}$, we adopted a limit of $27.0 \mathrm{~kg} / \mathrm{m}^{2}$ to enable a meaningful evaluation of the relative benefits or otherwise of $\mathrm{MH}$ in overweight individuals: with a lower limit of BMI of $\geq 25.0 \mathrm{~kg} / \mathrm{m}^{2}$, the Cox model hazard ratio for OWOB as a predictor of CVD mortality (101 CVD deaths before exclusions) was 1.32 , 95\% CI: $0.90-1.94, P=0.1$, whereas with a lower limit of BMI of $\geq 27.0 \mathrm{~kg} / \mathrm{m}^{2}$, the hazard ratio was $1.95,95 \% \mathrm{CI}$ : $1.33-2.87, P=0.001$. A lower limit of $27 \mathrm{~kg} / \mathrm{m}^{2}$ therefore provided for an appreciably higher risk background against which to distinguish whether $\mathrm{MH}$ OWOB individuals were or were not at increased risk relative to MH NW individuals.

\section{Cardiovascular disease and total mortality ascertainment}

Deaths in the UK were identified through the NHS Information Centre for Health and Social Care. Deaths overseas were notified by family members of the deceased and by the company for which the health screening programme was undertaken. Mortality information was complete to 1 January 2014, with the exception of 27 individuals who are no longer traceable. Fifteen of the 27 who were lost to mortality follow-up were also lost to any further clinical follow-up after their first study visit and therefore had zero follow-up time. Mean mortality follow-up time in the remaining 1176 was 25.7 years (range $0.5-42.5$ years).

Death from CVD was assigned if myocardial infarction, coronary artery disease or thrombosis, cerebrovascular incident, stroke, peripheral vascular disease or aortic aneurysm (ICD-10 codes I20-I25; I63-I67 and I70-I73) was recorded as a primary cause of death.

\section{Statistical analysis}

Participants with pre-existing CVD or incomplete data for BMI, blood pressure, triglycerides, HDL-C, FPG and LDL-C were excluded. FPG and FPI concentrations were calculated as the mean of the two fasting measurements. The homeostasis model assessment index of insulin resistance (HOMA-IR) (22) and the Matsuda index of insulin sensitivity (Matsuda-SI) (23) were calculated.

Statistical analyses were carried out using StataCorp. 2013 (Stata Statistical Software: Release 13. College Station, TX: StataCorp LP). Risks of CVD and total mortality in $\mathrm{MH}$ or MUH OWOB participants relative to their NW equivalents were evaluated by Cox proportional hazards modelling with adjustment for age, smoking, alcohol and exercise (as categorised above) to diminish any confounding effect these covariates might have on relationships between adiposity, metabolic health and CVD mortality risk. Primary analyses concerned relationships between baseline characteristics and CVD and total mortality risks. Secondary analyses included follow-up information, with OWOB and confounding variables treated as discrete, time-varying covariates. Kruskal-Wallis analysis of variance, the Mann-Whitney test and the proportions test were applied as appropriate. The number of participants decreased with increasing number of follow-up visits. Therefore, analyses were undertaken for visits 1-2 in the sub-group of individuals 
with 2 or more visits, for visits $1-3$ in the sub-group of individuals with 3 or more visits, through to visits 1-10 in the sub-group of individuals with 10 or more visits. In this way, numbers of observations at each visit within each number-of-visits sub-group were the same. Risk of transition from MH to MUH was evaluated by Cox proportional hazards modelling in three models according to the 'naïve' and 'longitudinal' approaches distinguished by Twisk et al. (24). In Model 1, time to first occurrence of MUH in those $\mathrm{MH}$ at baseline was predicted by baseline OWOB status and covariates. In Models 2 and 3, MUH was treated as a recurrent event in the full dataset and predicted, according to the Andersen-Gill model (25), by OWOB status and covariates either at baseline (Model 2) or as discrete, time-varying covariates (Model 3).

\section{Results}

Characteristics at first visit for the 1191 participants in the cohort are summarised in Table 1. Exclusions due to existing CVD or missing metabolic health variables are summarised in Supplementary Fig. 1 (see section on supplementary data given at the end of this article). After exclusions, there were 1099 participants with a first visit with complete data for BMI, LDL-C, TG, HDL-C, blood pressure and FPG. Median age was 46.6years, (range 25-70years) and median BMI $25.6 \mathrm{~kg} / \mathrm{m}^{2}$ (range $\left.18.1-46.9 \mathrm{~kg} / \mathrm{m}^{2}\right)$. Sixty-nine percent were non-smokers; $65 \%$ consumed $<28$ units/week of alcohol; $40 \%$ took no exercise and $41 \%$ undertook nonaerobic exercise. Prescription drug use at baseline was limited: 5 on glucoselowering agents, 3 on statins, 1 on a fibrate and 20 on blood pressure-lowering agents. Of the 1099 participants, 955 had a measurement of FPI as well as FPG and 631 had an OGTT with measures of plasma glucose and insulin.

\section{Criteria for metabolic health}

After exclusions, there were $87 \mathrm{CVD}$ deaths during a mean follow-up time of 24.6 years (range $0.5-42.5$ years, excluding nine participants lost to mortality follow-up and with no clinical follow-up). In univariate Cox proportional hazards modelling, each of the five defining risk factors for $\mathrm{MH}$ was a significant predictor of CVD and of total mortality (Supplementary Table 1). Nevertheless, in the presence of only a single risk factor of any type, risks of CVD and total mortality (unadjusted for factors contributing to risk factor variation) were not significantly raised (hazard ratio (HR) CVD mortality 1.66, 95\% CI:
Table 1 Cohort characteristics.

\begin{tabular}{|c|c|c|}
\hline & $\begin{array}{c}\text { No. } \\
\text { observations }\end{array}$ & Median (IQR)/\% (n) \\
\hline Age (year) & 1191 & $46.4(39.9-51.8)$ \\
\hline BMI $\left(\mathrm{kg} / \mathrm{m}^{2}\right)$ & 1182 & $25.6(23.7-27.4)$ \\
\hline $\mathrm{BMI} \geq 27.0 \mathrm{~kg} / \mathrm{m}^{2} \%(n)$ & 1182 & $30(350)$ \\
\hline $\begin{array}{l}\text { Fasting plasma glucose } \\
(\mathrm{mmol} / \mathrm{L})\end{array}$ & 1177 & $5.3(5.0-5.6)$ \\
\hline $\begin{array}{l}\text { Fasting plasma insulin } \\
(\mathrm{mU} / \mathrm{L})^{*}\end{array}$ & 1030 & $9.5(6.0-14.5)$ \\
\hline $\mathrm{SBP}(\mathrm{mmHg})$ & 1190 & $123(115-135)$ \\
\hline $\mathrm{DBP}(\mathrm{mmHg})$ & 1190 & $80(70-85)$ \\
\hline Total cholesterol & 1181 & $5.36(4.71-6.11)$ \\
\hline Triglycerides (mmol/L) & 1181 & $1.22(0.86-1.74)$ \\
\hline HDL cholesterol (mmol/L) & 1004 & $1.25(1.08-1.43)$ \\
\hline LDL cholesterol (mmol/L) & 1003 & $3.50(2.86-4.14)$ \\
\hline Uric acid ( $\mu \mathrm{mol} / \mathrm{L})$ & 1163 & $380(326-430)$ \\
\hline HOMA-IR & 1030 & $2.19(1.36-3.41)$ \\
\hline Matsuda-IS & 699 & $4.71(3.07-7.17)$ \\
\hline White cell count $\left(\times 10^{9}\right)$ & 699 & $4.71(3.07-7.17)$ \\
\hline ESR & 949 & $5.6(4.7-6.8)$ \\
\hline Family history of diabetes $\%(n)$ & 1181 & $35(411)$ \\
\hline $\begin{array}{l}\text { Family history of heart } \\
\text { disease } \%(n)\end{array}$ & 1181 & $8(93)$ \\
\hline Existing diabetes \% ( $n)$ & 1171 & $5(57)$ \\
\hline Smoking \% $(n)$ & 1184 & \\
\hline Non-smoker & & $67(797)$ \\
\hline$<15$ Cigarettes/day & & $20(241)$ \\
\hline$\geq 15$ Cigarettes/day & & $12(146)$ \\
\hline Alcohol \% (n) & 1179 & \\
\hline$<28$ U/week & & $64(753)$ \\
\hline$\geq 28$ U/week & & $36(426)$ \\
\hline Exercise \% $(n)$ & 1126 & \\
\hline No exercise & & $41(460)$ \\
\hline Nonaerobic & & $41(457)$ \\
\hline Aerobic & & $18(209)$ \\
\hline \multicolumn{3}{|l|}{ Current drug use $\%(n)$} \\
\hline Glucose lowering & 1191 & $0.3(4)$ \\
\hline Lipid lowering & 1191 & \\
\hline Statin & & $0.3(4)$ \\
\hline Fibrate & & $0.3(3)$ \\
\hline Blood pressure lowering & 1191 & $2.2(26)$ \\
\hline Uric acid lowering & 1191 & $1.0(12)$ \\
\hline \multicolumn{3}{|l|}{ Mortality } \\
\hline Total mortality \% (n) & 1164 & $29(340)$ \\
\hline CVD mortality \% (n) & 1164 & $10(111)$ \\
\hline $\begin{array}{l}\text { Mortality follow-up time } \\
\text { (years) }\end{array}$ & 1176 & $24.8(18.6-32.9)$ \\
\hline
\end{tabular}

$0.62-4.48, P=0.3$; total mortality $1.51,95 \%$ CI: $0.95-2.40$, $P=0.08)$. With two risk factors, however, the hazard ratio became significant (HR CVD mortality $2.79,95 \%$ CI: $1.07-7.27, P=0.03$; total mortality 2.07 , $95 \%$ CI: 1.31 3.28, $P=0.002$ ). Therefore, our definition of $\mathrm{MH}$ allowed for $\leq 1$ of the five risk factors considered. Fifty-four percent of NW and $28 \%$ of OWOB individuals were identified as MH (Table 2). MH OWOB participants tended to smoke and drink more than MH NW. Despite being classified as $\mathrm{MH}$ according to the specified cut-offs, $\mathrm{MH}$ OWOB 
Table 2 Characteristics of individuals metabolically healthy (MH) or metabolically unhealthy (MUH) among normal-weight (NW) and overweight or obese (OWOB) participants. Median (IQR) for continuous variables, percentage $(n)$ for categorical variables. Significant differences between NW and OWOB in $\mathrm{MH}$ and MUH groups are shown.

Age (years)

BMI $\left(\mathrm{kg} / \mathrm{m}^{2}\right)$

Fasting plasma glucose (mmol/L)

Fasting plasma insulin $(\mathrm{mmol} / \mathrm{L})$

$\mathrm{SBP}(\mathrm{mmHg})$

DBP $(\mathrm{mmHg})$

Total cholesterol

Triglycerides ( $\mathrm{mmol} / \mathrm{L}$ )

HDL cholesterol ( $\mathrm{mmol} / \mathrm{L})$

LDL cholesterol ( $\mathrm{mmol} / \mathrm{L})$

Uric acid ( $\mu \mathrm{mol} / \mathrm{L})$

HOMA-IR

Matsuda-IS

White cell count $\left(\times 10^{9}\right)$

ESR

FH heart disease, $1^{\circ}$ relative $\%(n)$

FH diabetes, $1^{\circ}$ relative $\%(n)$

Diabetes \% (n)

Smoking \% $(n)$

Non-smoker

$<15$ Cigarettes/day

$\geq 15$ Cigarettes/day

Alcohol \% (n)

$<28 \mathrm{U} /$ week

$\geq 28 \mathrm{U} /$ week

Exercise \% ( $n)$

No exercise

Nonaerobic

Aerobic

Current drug use \% ( $n)$

Glucose lowering

Statin

Fibrate

Blood pressure lowering

Mortality

Total mortality \% (n)

CVD mortality \% (n)

Mortality follow-up time (years)

\begin{tabular}{|c|c|}
\hline \multicolumn{2}{|c|}{ МH } \\
\hline NW $(n=425)$ & OWOB $(n=90)$ \\
\hline $44.4(37.6-49.7)$ & $45.4(39.7-52.0)$ \\
\hline $24.2(22.5-25.4)$ & $28.2(27.8-29.3)$ \\
\hline $5.1(4.9-5.3)$ & $5.3(5.0-5.5)$ \\
\hline $7.5(5.0-11.5)$ & $11.0(7.5-15.5)$ \\
\hline $120(110-124)$ & $120(110-130)$ \\
\hline $70(70-80)$ & $80(70-84)$ \\
\hline $4.9(4.4-5.4)$ & $4.8(4.4-5.4)$ \\
\hline $0.96(0.72-1.23)$ & $1.11(0.76-1.46)$ \\
\hline $1.38(1.20-1.55)$ & $1.26(1.14-1.43)$ \\
\hline $3.01(2.55-3.59)$ & $2.95(2.60-3.32)$ \\
\hline $350(304-400)$ & 386 (340-449) \\
\hline $1.67(1.08-2.67)$ & $2.63(1.79-3.65)$ \\
\hline $6.03(4.29-8.24)$ & $3.87(2.84-4.78)$ \\
\hline $5.2(4.5-6.3)$ & $6.1(5.2-7.0)$ \\
\hline $3(2-6)$ & $4(2-6)$ \\
\hline $33(141)$ & $26(23)$ \\
\hline $8(32)$ & $8(7)$ \\
\hline $1(5)$ & 1 (1) \\
\hline 74 (313) & $60(53)$ \\
\hline $16(67)$ & $29(26)$ \\
\hline $10(44)$ & $11(10)$ \\
\hline 75 (314) & $59(53)$ \\
\hline $25(106)$ & 41 (37) \\
\hline $34(138)$ & $36(31)$ \\
\hline 43 (173) & $49(43)$ \\
\hline $23(95)$ & $15(13)$ \\
\hline $0(0)$ & $1(1)$ \\
\hline $0(0)$ & $0(0)$ \\
\hline $0(0)$ & $0(0)$ \\
\hline $0.5(2)$ & $1.1(1)$ \\
\hline $18(77)$ & $23(21)$ \\
\hline $5(21)$ & $2(2)$ \\
\hline $24.9(18.7-32.9)$ & $22.3(17.4-29.5)$ \\
\hline
\end{tabular}

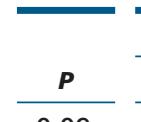

0.09

0.001

$<0.001$

0.004

$<0.001$

0.5

0.007

0.002

0.6

$<0.001$

$<0.001$

$<0.001$

$<0.001$

0.08

0.3

0.9

0.9

0.009

0.002

0.2

.2

\begin{tabular}{c}
\hline \\
NW $(n=358)$ \\
\hline $46.9(42.3-53.4)$ \\
$24.8(23.8-26.0)$ \\
$5.4(5.1-5.8)$ \\
$9.2(6.0-14.5)$ \\
$130(120-140)$ \\
$80(75-90)$ \\
$5.9(5.3-6.4)$ \\
$1.45(1.04-1.98)$ \\
$1.22(1.04-1.40)$ \\
$3.89(3.43-4.40)$ \\
$380(330-420)$ \\
$2.27(1.41-3.47)$ \\
$4.37(3.04-6.66)$ \\
$5.7(4.8-7.1)$ \\
$5(2-8)$ \\
$38(135)$ \\
$8(29)$ \\
$5(19)$ \\
\end{tabular}

65 (231)

$22(78)$

$13(46)$

59 (209)

$41(145)$

$41(138)$

41 (137)

$18(59)$

$0.9(3)$

$0.3(1)$

$0(0)$

$2.2(8)$

34 (122)

$10(35)$

0.2

0.008
MUH

$\frac{\text { OWOB }(n=226)}{48.0(42.5-53.8)} \frac{P}{0.7}$

$28.7(27.7-30.6) \quad<0.001$

$5.5(5.2-5.9) \quad 0.1$

$13.0(9.5-18.5) \quad<0.001$

$130(120-140) \quad 0.3$

$85(80-90) \quad 0.004$

$5.8(5.2-6.6) \quad 0.7$

$1.78(1.31-2.55)<0.001$

$1.12(0.96-1.27)<0.001$

$3.72(3.27-4.32) \quad 0.1$

$410(359-460)<0.001$

$3.29(2.26-4.68)<0.001$

$2.70(1.90-4.23)<0.001$

$5.8(5.0-6.9) \quad 0.2$

$5(2-10) \quad 0.4$

$37(83) \quad 0.2$

$8(17) \quad 0.8$

$5(12) \quad 0.9$

0.3

0.8

0.1

50 (111)

36 (79)

$14(32)$

$0.4(1)$

$0.9(2)$

$0.4(1)$

$4.0(9)$

0.5

0.3

0.2

0.2

0.5

0.2

0.002 participants tended to have higher FPG, blood pressure, triglycerides and uric acid and lower HDL cholesterol than MH NW and similar differentials were apparent between MUH OBOW and MUH NW participants. Among OBOW participants, those who were $\mathrm{MH}$ were slightly younger and took more exercise than the MUH, but tended to smoke more and have higher alcohol intake.

\section{Insulin sensitivity and sub-clinical inflammation in metabolically healthy NW and OWOB}

MH OWOB participants had markedly higher insulin resistance than $\mathrm{MH}$ NW, 57\% higher according to
HOMA-IR and 56\% higher according to Matsuda-IS (Table 2). Similar differentials were also seen between MUH OWOB and NW participants. White cell count was also significantly increased in $\mathrm{MH}$ OWOB participants compared with $\mathrm{MH}$ NW, but this difference was not apparent in MUH participants. ESR showed relatively minor variation, however.

\section{Metabolic health and CVD and total mortality in NW and OWOB}

Independently of age, smoking, alcohol intake and exercise habit, OWOB was a significant predictor of 
both CVD (HR 1.76, 95\% CI: 1.26-2.44, $P=0.001$ ) and total (HR 1.38, 95\% CI: 1.13-1.67, $P=0.001$ ) mortality. However, among those who were $\mathrm{MH}$, OWOB ceased to be an independent predictor of CVD mortality (HR 1.13, 95\% CI: $0.34-3.72, P=0.8$ ). An effect on total mortality was, nevertheless, still apparent (HR 1.60, 95\% CI: 1.042.47, $P=0.03$ ). In the full dataset (3129 observations), with OWOB and confounding factors treated as discrete, time-varying covariates, OWOB was again a significant, independent predictor of both CVD (HR 2.02, 95\% CI: 1.27-3.21, $P=0.003$ ) and total (HR 1.55, 95\% CI: 1.20 2.01, $P=0.001)$ mortality. Among those who were $\mathrm{MH}$ at baseline, however, OWOB was a risk factor for neither CVD (HR 0.64, 95\% CI: 0.15-2.83, $P=0.5$ ) nor total (HR $1.38,95 \%$ CI: $0.83-2.90, P=0.2)$ mortality. In contrast to those who were $\mathrm{MH}$, among participants who were $\mathrm{MUH}$ at baseline, OWOB remained an independent predictor of mortality with hazard ratios of 1.67 (95\% CI: 1.17-2.39, $P=0.004)$ and 1.26 (95\% CI: $1.01-1.57, P=0.03)$ for CVD and total mortality respectively, and these risks were equally apparent when the full dataset with covariate follow-up was considered.

\section{Prevalence of MH during follow-up}

Of the 1099 participants included in this analysis, $608 \mathrm{had}$ a second visit, 404 a third down to 32 with 10 visits. Mean follow-up time between visits 1 and 2 was 3.7 years and ranged between subsequent visits from 2.1 to 2.7 years. Of the 316 participants who were OWOB at their first visit, 160 had one subsequent visit, 96 two subsequent visits to 9 with 10 subsequent visits.

Baseline prevalence of $\mathrm{MH}$ was $54 \%$ among the 783 NW participants and $28 \%$ among the 316 OWOB participants (Supplementary Table 3). In the sub-group of 32 participants who returned for 10 or more visits, the baseline prevalence of $\mathrm{MH}$ was 39\% in NW and $44 \%$ in OBOW individuals and at visit $10,33 \%$ and $38 \%$. In OWOB individuals, there was a trend towards increased prevalence of $\mathrm{MH}$ from visits 1-3 (average prevalences across number-of-visits sub-groups, weighted by numbers of observations in each sub-group, were 30, 35 and 43\% for visits 1-3 respectively), with an irregular decline in prevalence thereafter. Among individuals OWOB at baseline, baseline prevalences of $\mathrm{MH}$ in individuals in number-of-visits sub-groups 1-10 were 28, 26, 31, 35, $33,35,38,34,41$ and $44 \%$ respectively, indicating that those who subsequently returned for increasing numbers of follow-up visits had an increased prevalence of $\mathrm{MH}$ from the outset.

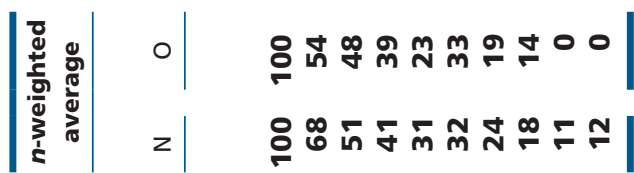

$\frac{n}{\frac{n}{5}}|0|+$

윤 $\stackrel{n}{N} \stackrel{n}{N} 000000$

$\stackrel{+}{\circ}|a|$

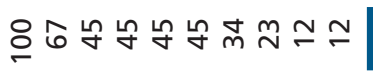

\begin{tabular}{l|l|l|}
$\frac{y}{5}$ & 0 & $\wedge \mid$ \\
$\frac{5}{2}$ & \\
$\vdots$ & $z|\approx|$
\end{tabular}

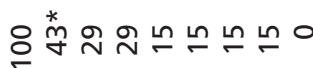

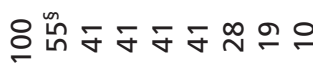

\begin{tabular}{l|l|l}
$\frac{n}{5}$ & 0 & $=$ \\
$\frac{5}{2}$ & $=$ \\
+ & $z$ & $\approx$
\end{tabular}

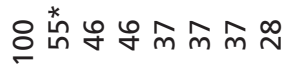

ஓㅇํ워

\begin{tabular}{l|l|l|}
$\frac{n}{2}$ & 0 & 年 \\
$\frac{5}{2}$ & & \\
+ & $z$ & 8
\end{tabular}

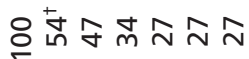

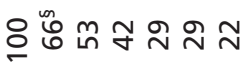

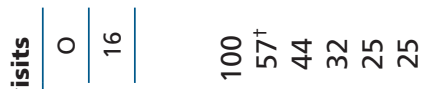

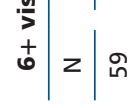

응ํำนกำ

\begin{tabular}{l|l|l}
$\frac{n}{5}$ & 0 & $=$ \\
$\frac{5}{5}$ & & $=$ \\
$+\frac{1}{n}$ & $z$ & $\approx$
\end{tabular}

음ํํํㅇํำ 웅

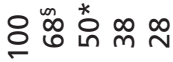

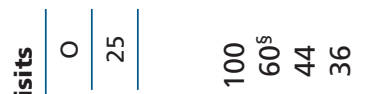

\begin{tabular}{l|l}
+ \\
+
\end{tabular}$|z| \stackrel{\infty}{\circ} \mid$

은 눈우

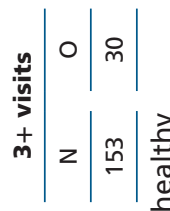

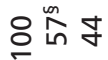

¿

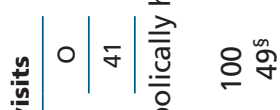

$\frac{5}{3}$

$\stackrel{+}{\sim}|z| \stackrel{\sim}{\sim} \mid$

은

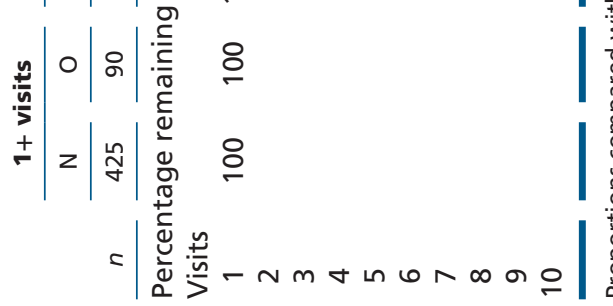


$\%$ remaining metabolically healthy
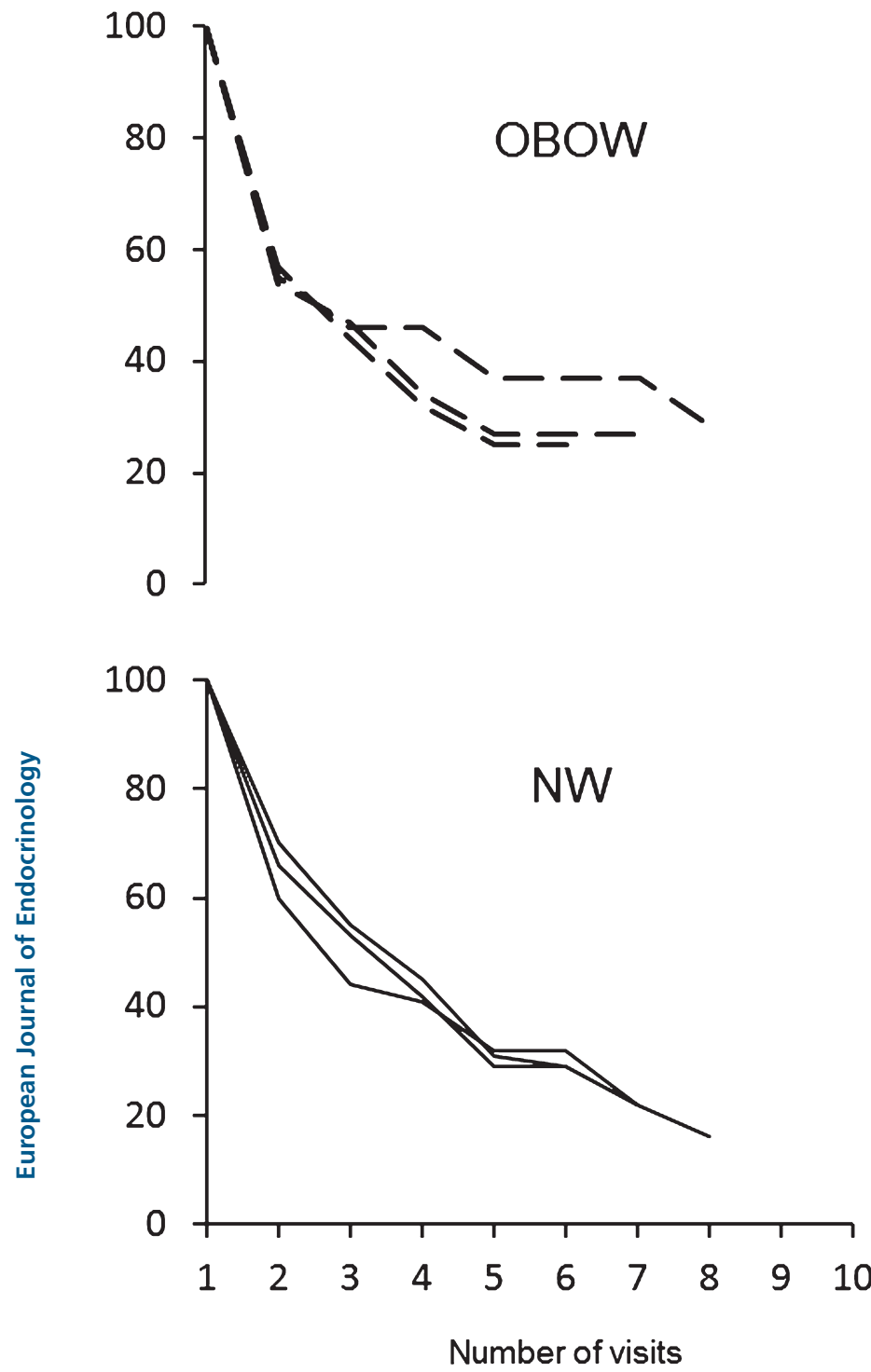

Figure 1

Proportions of individuals overweight or obese (OWOB-dashed line) or normal weight (NW-solid line) and metabolically healthy at baseline remaining metabolically healthy. Attrition of metabolic health is illustrated by plotted series of observations for sub-groups that had 6 or more, 7 or more or 8 or more visits.

\section{Changes in MH status during follow-up}

A constant prevalence from one visit to the next might be sustained by equal numbers transitioning from $\mathrm{MH}$ to MUH and from MUH to MH. Therefore, we analysed proportions of individuals $\mathrm{MH}$ at baseline who remained $\mathrm{MH}$ at successive visits. Proportions of individuals $\mathrm{MH}$ and OWOB at baseline who remained $\mathrm{MH}$ at visit 2 varied between 49 and $60 \%$ for number-of-visits subgroups 1-8 (sub-groups 9 and 10 having unreliably small numbers of observations: $n<10$ ), with little evidence of any trend (Table 3). For NW individuals, the range for number-of-visits sub-groups 1-10 was between 60 and $71 \%$. Weighted average proportions of individuals OWOB and $\mathrm{MH}$ at baseline who remained $\mathrm{MH}$ at visits 2, 3 and 4 were 54, 48 and 39\% respectively. From visit 5 onwards, proportions remaining $\mathrm{MH}$ continued to decline, but, overall, only the difference in proportions between visits 1 and 2 was statistically significant. Proportions of individuals NW and $\mathrm{MH}$ at baseline who remained $\mathrm{MH}$ at visits 2, 3 and 4 were 68,51 and $41 \%$, with the difference in proportions between visits 1 and 2 being generally significant at $P<0.001$ and between visits 2 and 3 , at $P<0.05$. Initially, the rate of attrition of individuals remaining $\mathrm{MH}$ was faster among individuals OWOB at baseline than among those NW (Fig. 1), and for those with $\geq 2$ visits, the proportion of OWOB individuals remaining $\mathrm{MH}$ at visit 2 was significantly lower than the proportion of NW individuals remaining MH $(P=0.007)$. However, beyond visit 2 , proportions of OWOB and NW participants remaining $\mathrm{MH}$ converged. For those with $\geq 3$ visits, analysis of individuals remaining MH was repeated with visit 2 as baseline, and for those with $\geq 4$ visits, visit 3 as baseline. Findings were generally consistent with the analysis with an individual's visit 1 as baseline (Table 4).

\section{Changes in weight and lifestyle during follow-up}

For those with $\geq 2$ visits, $29 \%$ of those OWOB at visit 1 were NW at visit 2 . For those with $\geq 3$ visits, $15 \%$ of those

Table 4 Weighted average percentages of individuals metabolically healthy at baseline remaining metabolically healthy. Data for up to 3 visits subsequent to the baseline visit are shown, with baseline visits taken as an individual's first, second or third visit. Weighted average percentages derive from subsets of individuals with 2, 3, 4 to 10 or more visits.

\begin{tabular}{lccc}
\hline & \multicolumn{3}{c}{$\%$ remaining metabolically healthy } \\
\cline { 2 - 3 } Baseline visit & 2nd visit & 3rd visit & 4th visit \\
\hline Normal weight & 68 & 51 & 41 \\
$\quad$ Visit 1 & 68 & 47 & 38 \\
Visit 2 & 66 & 54 & 49 \\
$\quad$ Visit 3 & & & \\
Overweight or obese & 54 & 48 & 39 \\
Visit 1 & 70 & 55 & 39 \\
Visit 2 & 56 & 39 & 41 \\
Visit 3 & &
\end{tabular}


OWOB at visit 2 were NW at visit 3 . For those with $\geq 4$ visits, $23 \%$ of those $\mathrm{OWOB}$ at visit 3 were NW at visit 4 . Equivalent figures for NW individuals becoming OWOB were 6,8 and $7 \%$. For visits 5-10, proportions ranged between 6 and 16\% for OWOB switching to NW and 0 and $9 \%$ for NW to OWOB. Transition from OWOB to NW tended to be associated with transition from MUH to $\mathrm{MH}$, although the majority did not change status (results not shown). For the transition from NW to OWOB, again, the majority did not change status. Transitions in smoking, alcohol consumption and exercise were also explored (results not shown). There was a tendency towards reduction in smoking over successive visits but with no clear association with change in $\mathrm{MH}$ status. On Cox proportional hazards modelling of incident MUH in the dataset including follow-up visits, only increasing age was a consistent predictor of transition to MUH in those $\mathrm{MH}$ at baseline (Model 1: HR: 1.06, 95\% CI: 1.03-1.08, $P<0.001$; Model 2: HR: 1.05, 95\% CI: 1.03-1.07, $P<0.001$; Model 3: HR 1.03, 95\% CI: 1.01-1.04, $P<0.001)$. There was some evidence for moderate exercise reducing risk of transition to MUH (Model 1: HR: 0.70, 95\% CI: 0.47-1.02, $P=0.06$; Model 2: HR: 0.73, 95\% CI: 0.57-0.93, $P=0.01$ ) and for heavy smoking increasing risk (Model 3: HR: 1.47, 95\% CI: 0.99-2.16, $P=0.05)$, but, importantly, there was no evidence from any of these analyses that among those $\mathrm{MH}$ at baseline those who were OWOB were at an overall increased risk of becoming MUH subsequently.

\section{Discussion}

We evaluated three hypotheses. The first was that $\mathrm{MH}$ OWOB individuals are at greater risk of CVD mortality than MH NW individuals. This was not the case. Other studies $(11,26)$ have noted that MH OWOB individuals tend to appear somewhat healthier in terms of weight and lifestyle characteristics than their MUH counterparts, although in our study, this was only apparent with regard to exercise; smoking and alcohol intake tended to be greater in the MH OWOB participants. Overall, however, risk differentials were independent of lifestyle covariates, which accords with the possibility that among OWOB individuals, a low CVD risk sub-group can indeed be distinguished using $\mathrm{MH}$ criteria and supports the concept of metabolically healthy overweight or obesity and this low risk may extend to total mortality.

The second hypothesis was that MHOWOB individuals are insulin resistant and exhibit sub-clinical inflammation relative to $\mathrm{MH} \mathrm{NW}$ individuals. This was the case and, with regard to inflammation, accords with a previous report of increased inflammation in MHO individuals (27). This could suggest that further discrimination of $\mathrm{MH}$ among OWOB individuals may be possible using measures of insulin resistance and sub-clinical inflammation. However, our finding that $\mathrm{MH}$ OWOB individuals were at no greater risk of CVD mortality than $\mathrm{MH}$ NW individuals suggests that such further discrimination may add little to CVD risk evaluation, consistent with CVD risk associated with increasing adiposity being fully explained by established risk factors (28). However, although increased sub-clinical inflammation in $\mathrm{MHO}$ may be relatively benign with regard to CVD risk, the increased insulin resistance may indicate increased risk of type 2 diabetes $(26,29,30)$.

Our third hypothesis was that $\mathrm{MH}$ in OWOB individuals is a persistent trait, sustained over long-term follow-up. Against this, from visit 1 to 2, fully 51\% of $\mathrm{MH}$ individuals who were OWOB and $29 \%$ of those who were NW and at visit 1 were MUH at visit 2. Subsequently, over two decades of follow-up and with up to 10 visits, only about 30\% of individuals either OWOB or NW and $\mathrm{MH}$ at baseline remained consistently $\mathrm{MH}$. Moreover, similar percentages transitioned from MUH to MH over the course of these visits (results not shown). That $\mathrm{MH}$ is susceptible to this degree of variability does not appear to have been realised in previous studies of $\mathrm{MHO}$ or $\mathrm{MH}$ OWOB.

Our long-term $\mathrm{MH}$ profiles therefore indicate appreciable intra-individual variation in $\mathrm{MH}$ status, and this would be expected from the individual variation exhibited by the variables used to categorise $\mathrm{MH}$ status (31). Use of a categorical criterion, deriving from a continuous measure of a biologically variable parameter, measured on a single occasion to classify individuals as having or not having a condition is highly susceptible to regression towards the mean, and judging by the marked attrition in $\mathrm{MH}$ individuals from visit 1 to 2 , this had considerable impact on $\mathrm{MH}$ categorisation. Beyond visit 2 , however, the rate of attrition of individuals consistently $\mathrm{MH}$ was reduced somewhat. Importantly, however, in survival analysis with incident MUH as outcome, among those who were $\mathrm{MH}$ at baseline, OWOB was entirely unrelated to transition to $\mathrm{MUH}$; moreover, transition to MUH could not be accounted for by weight gain and was only associated with lifestyle change to a limited extent, consistent with $\mathrm{MH}$ at baseline being, to some extent, a stable characteristic. We may, therefore, infer that each participant in the study had an underlying degree of metabolic health that was further from or closer to the categorical cut-offs applied to define MH. Those far from the cut-offs would have tended to retain $\mathrm{MH}$ or $\mathrm{MUH}$ 
status, whereas those close to the cut-off would have transitioned from one state to another over time. It is noteworthy, however, that the proportion of individuals transitioning from $\mathrm{MH}$ to $\mathrm{MUH}$ from visit 1 to 2 was significantly greater among OWOB than among NW individuals. Possibly, given that $\mathrm{MH}$ was less prevalent among OWOB individuals, classifications of $\mathrm{MH}$ at baseline might be more susceptible to greater extremes of variation, which would be more likely to relapse into MUH at a second visit.

A number of previous studies have evaluated CVD risk in $\mathrm{MH}$ OB. In accord with our findings, despite inconsistencies in the definitions of $\mathrm{MH}$, the majority have found CVD risk to not be increased in $\mathrm{MH} \mathrm{OB}$ compared with MH NW individuals $(18,26,29,32,33,34,35)$, or have found CVD risk to be lower in MH OB compared with MUH OB (36), but not all studies agree (10). Moreover, several studies have found evidence for increased risk in MH OB compared with MH NW individuals in studies with $>15$ years follow-up $(17,19,37)$. However, our findings, which concerned CVD mortality over $>20$ years of follow-up, did not bear this out.

Few previous studies have included a follow-up evaluation of $\mathrm{MH}$ status. Appleton et al. undertook baseline and follow-up evaluation in a population sample of 3743 individuals over a median of 8.2 years with $61 \%$ providing clinic data at follow-up (26). In agreement with our findings, a significantly higher proportion of $\mathrm{MH} \mathrm{OB}$ than MH NW individuals were MUH at a second visit and risk of CVD in the $\mathrm{MH} \mathrm{OB}$ was no greater than in $\mathrm{MH}$ NW individuals. Also, in accord with our findings, the proportion of individuals $\mathrm{MHO}$ at baseline becoming $\mathrm{MUH}$ at follow-up was substantial at 30\%. Likewise, Soriguer et al., in a study of 1051 individuals, found that $48 \%$ of those MH OB at baseline were MUH at a 6-year follow-up (30). However, in neither of these studies was the time profile of attrition of $\mathrm{MH}$ distinguished, there being only a single follow-up estimate of change in $\mathrm{MH}$ status.

A limitation of our study was the relatively small sample size, potentially exacerbated by exclusion of 92 participants due to missing data. Analysis of the dataset with imputation of missing values resulted in identical findings with regard to CVD mortality (results not shown). However, with the imputed dataset, having 1 risk factor was associated with increased risk of total mortality. Further sub-analysis with $\mathrm{MH}$ defined by having no risk factors confirmed relative protection for total mortality among MH OWOB individuals, but there were no CVD deaths among OWOB participants with no risk factors. It should be acknowledged that the non-significant hazard ratio of 1.66 we observed for CVD mortality among those with a single risk factor could become statistically significant with greater numbers, so our definition of metabolic health must be regarded as relative and no more than a working definition. It should also be acknowledged that allowing for a single risk factor in our definition of $\mathrm{MH}$ could lead to inclusion of people with diabetes as metabolically healthy. This might seem unjustified; however, it should be borne in mind that a participant with diabetes as a sole risk factor would have to have been free of abnormalities in all other risk factors and not be taking lipid- or blood pressure-lowering agents. In any case, exclusion of people with diabetes from our analysis made no difference to our findings (results not shown). The small numbers of clinical outcomes meant that we could not systematically analyse CVD risk according to change in $\mathrm{MH}$ status, as has been done in one previous study, which was able to demonstrate that risk of CVD in the MHO was no greater than in $\mathrm{MH} \mathrm{NW}$ individuals regardless of subsequent transition to $\mathrm{MUH}$ (26). Nevertheless, in accord with this, we could conclude that despite appreciable transitioning between $\mathrm{MH}$ and MUH, OBOW individuals who were $\mathrm{MH}$ at baseline were not at increased risk. Limitations also included the highly selected group, which limits generalisability, although its homogeneity represents a strength with respect to hypothesis testing. Another limitation was the progressive loss to follow-up with regard to metabolic testing. It should be noted that our follow-up was undertaken in the context of a health program and there was evidence for weight loss in the cohort overall. Weight loss might have been expected to reduce transitioning from $\mathrm{MH}$ to $\mathrm{MUH}$ and possibly contributed to an increase in the prevalence of $\mathrm{MH}$ among individuals $\mathrm{OBOW}$ at baseline up to visit 3 .

In conclusion, our findings indicate appreciable individual variability and regression towards the mean when $\mathrm{MH}$ status is assigned by widely used criteria. $\mathrm{MH}$ among $\mathrm{OW}$ and $\mathrm{OB}$ individuals was associated with increased insulin resistance and sub-clinical inflammation compared with MH NW individuals. Nevertheless, despite these differences, OWOB individuals classified as $\mathrm{MH}$ at baseline according to either definition of $\mathrm{MH}$ were at no greater risk of CVD mortality over two decades of follow-up than MH NW individuals, supporting the possibility that a discrete category of metabolically healthy overweight or obesity can be distinguished.

\section{Supplementary data}

This is linked to the online version of the paper at http://dx.doi.org/10.1530/ EJE-16-0095. 
Declaration of interest

The authors declare that there is no conflict of interest that could be perceived as prejudicing the impartiality of the research reported.

\section{Funding}

Data acquisition for the HDDRISC study was funded by the Heart Disease and Diabetes Research Trust and the Rosen Foundation.

\section{Author contribution statement}

A K: statistical analysis, manuscript writing; D G J: analysis plan and manuscript development, IFG analysis plan, statistical analysis, manuscript writing.

\section{Acknowledgements}

The HDDRISC study was initiated by late Professor Victor Wynn, who directed it for much of its course and was funded by the Heart Disease and Diabetes Research Trust and the Rosen Foundation. Data acquisition was sustained by many clinical, scientific, technical, nursing and administrative staff, to each of whom we would like to extend our thanks.

\section{References}

1 Ruderman NB, Schneider SH \& Berchtold P. The "metabolicallyobese," normal-weight individual. American Journal of Clinical Nutrition 198134 1617-1621.

2 Andres R. Effect of obesity on total mortality. International Journal of Obesity 19804 381-386.

3 Sims EA. Are there persons who are obese, but metabolically healthy? Metabolism 200150 1499-504. (doi:10.1053/meta.2001.27213)

4 van Vliet-Ostaptchouk JV, Nuotio ML, Slagter SN, Doiron D, Fischer K, Foco L, Gaye A, Gögele M, Heier M, Hiekkalinna T et al. The prevalence of metabolic syndrome and metabolically healthy obesity in Europe: a collaborative analysis of ten large cohort studies. BMC Endocrine Disorders 201414 9. (doi:10.1186/1472-6823-14-9)

5 Pataky Z, Bobbioni-Harsch E \& Golay A. Open questions about metabolically normal obesity. International Journal of Obesity 201034 (Supplement 2) S18-S23. (doi:10.1038/ijo.2010.235)

6 Phillips CM. Metabolically healthy obesity: definitions, determinants and clinical implications. Reviews in Endocrine \& Metabolic Disorders 201314 219-227. (doi:10.1007/s11154-013-9252-x)

7 Stefan N, Häring HU, Hu FB \& Schulze MB. Metabolically healthy obesity: epidemiology, mechanisms, and clinical implications. Lancet Diabetes \& Endocrinology 20131 152-162. (doi:10.1016/S22138587(13)70062-7)

8 Blüher M. Are metabolically healthy obese individuals really healthy? European Journal of Endocrinology 2014171 R209-R219. (doi:10.1530/ EJE-14-0540)

9 Godsland IF, Leyva F, Worthington M, Walton C \& Stevenson JC. Associations of smoking, alcohol and physical activity with risk factors for coronary heart disease and diabetes in the first follow-up cohort of the HDDRISC Study (HDDRISC-1). Journal of Internal Medicine 1998244 33-41.

10 Kuk JL \& Ardern CI. Are metabolically normal but obese individuals at lower risk for all-cause mortality? Diabetes Care 2009322297 2299. (doi:10.2337/dc09-0574)

11 Ortega FB, Lee DC, Katzmarzyk PT, Ruiz JR, Sui X, Church TS \& Blair SN. The intriguing metabolically healthy but obese phenotype: cardiovascular prognosis and role of fitness. European Heart Journal 201334 389-397. (doi:10.1093/eurheartj/ehs174)
12 Marini MA, Frontoni S, Succurro E, Arturi F, Fiorentino TV, Sciacqua A, Perticone F \& Sesti G. Differences in insulin clearance between metabolically healthy and unhealthy obese subjects. Acta Diabetologica 201451 257-261. (doi:10.1007/s00592-0130511-9)

13 Executive summary of the third report of the National Cholesterol Education Program (NCEP) Expert Panel on Detection, Evaluation and Treatment of High Blood Cholesterol in Adults (Adult Treatment Panel III). JAMA 2001285 2486-2497.

14 Alberti KG, Zimmet P, Shaw J \& IDF-Epidemiology-Task-ForceConsensus-Group. The metabolic syndrome - a new worldwide definition. Lancet 2005366 1059-1062. (doi:10.1016/S01406736(05)67402-8)

15 Vukovic R, Milenkovic T, Mitrovic K, Todorovic S, Plavsic L, Vukovic A \& Zdravkovic D. Preserved insulin sensitivity predicts metabolically healthy obese phenotype in children and adolescents. European Journal of Pediatrics 2015174 1649-1655. (doi:10.1007/s00431-0152587-4)

16 Wildman RP, Muntner P, Reynolds K, McGinn AP, Rajpathak S, WylieRosett J \& Sowers MR. The obese without cardiometabolic risk factor clustering and the normal weight with cardiometabolic risk factor clustering: prevalence and correlates of 2 phenotypes among the US population (NHANES 1999-2004). Archives of Internal Medicine 2008 168 1617-1624. (doi:10.1001/archinte.168.15.1617)

17 Hinnouho GM, Czernichow S, Dugravot A, Batty GD, Kivimaki M \& Singh-Manoux A. Metabolically healthy obesity and risk of mortality: does the definition of metabolic health matter? Diabetes Care 201336 2294-2300. (doi:10.2337/dc12-1654)

18 Kip KE, Marroquin OC, Kelley DE, Johnson BD, Kelsey SF, Shaw LJ, Rogers WJ \& Reis SE. Clinical importance of obesity versus the metabolic syndrome in cardiovascular risk in women: a report from the Women's Ischemia Syndrome Evaluation (WISE) study. Circulation 200417 706-713. (doi:10.1161/01.CIR.0000115514.44135.A8)

19 Ärnlöv J, Ingelsson E, Sundström J \& Lind L. Impact of body mass index and the metabolic syndrome on the risk of cardiovascular disease and death in middle-aged men. Circulation 2010121 230-236. (doi:10.1161/CIRCULATIONAHA.109.887521)

20 Durward CM, Hartman TJ \& Nickols-Richardson SM. All-cause mortality risk of metabolically healthy obese individuals in NHANES III. Journal of Obesity 20122012 460321. (doi:10.1155/2012/460321)

21 Choi KM, Cho HJ, Choi HY, Yang SJ, Yoo HJ, Seo JA, Kim SG, Baik SH, Choi DS \& Kim NH. Higher mortality in metabolically obese normalweight people than in metabolically healthy obese subjects in elderly Koreans. Clinical Endocrinology 201379 364-370. (doi:10.1111/ cen.2013.79.issue-3)

22 Matthews DR, Hosker JP, Rudenski AS, Naylor BA, Treacher DF $\&$ Turner RC. Homeostasis model assessment: insulin resistance and $B$-cell function from fasting plasma glucose and insulin concentrations in man. Diabetologia 198528 412-419. (doi:10.1007/ BF00280883)

23 Matsuda M \& DeFronzo RA. Insulin sensitivity indices obtained from oral glucose tolerance testing. Diabetes Care 199922 1462-1470.

24 Twisk J, Smidt N \& de Vente W. Applied analysis of recurrent events: a practical overview. Journal of Epidemiology and Community Health 2005 59 706. (doi:10.1136/jech.2004.030759)

25 Andersen P \& Gill R. Cox's regression model for counting processes: a large sample study. Annals of Statistics 198210 1100-1120.

26 Appleton SL, Seaborn CJ, Visvanathan R, Hill CL, Gill TK, Taylor AW, Adams RJ \& the North West Adelaide Health Study Team. Diabetes and cardiovascular disease outcomes in the metabolically healthy obese phenotype: a cohort study. Diabetes Care 201336 2388-2394. (doi:10.2337/dc12-1971)

27 Gómez-Ambrosi J, Catalán V, Rodríguez A, Andrada P, Ramírez B, Ibzáñez P, Vila N, Romero S, Margall MA, Gil MJ et al. Increased cardiometabolic risk factors and inflammation in adipose tissue in 
obese subjects classified as metabolically healthy. Diabetes Care 2014 37 2813-2821. (doi:10.2337/dc14-0937)

28 The Emerging Risk Factors Collaboration, Wormser D, Kaptoge S, Di Angelantonio E, Wood AM, Pennells L, Thompson A, Sarwar N, Kizer JR, Lawlor DA et al. Separate and combined associations of body-mass index and abdominal adiposity with cardiovascular disease: collaborative analysis of 58 prospective studies. Lancet 2011 377 1085-1095. (doi:10.1016/S0140-6736(11)60105-0)

29 Meigs JB, Wilson PW, Fox CS, Vasan RS, Nathan DM, Sullivan LM $\&$ D'Agostino RB. Body mass index, metabolic syndrome, and risk of type 2 diabetes or cardiovascular disease. Journal of Clinical Endocrinology and Metabolism 200691 2906-2912. (doi:10.1210/ jc.2006-0594)

30 Soriguer F, Gutiérrez-Repiso C, Rubio-Martín E, García-Fuentes E, Almaraz MC, Colomo N, Esteva de Antonio I, de Adana MS, Chaves FJ, Morcillo S et al. Metabolically healthy but obese, a matter of time? Findings from the prospective Pizarra study. Journal of Clinical Endocrinology and Metabolism 201398 2318-2325. (doi:10.1210/jc.2012-4253)

31 Godsland IF. Intra-individual variation: significant changes in parameters of lipid and carbohydrate metabolism in the individual and intra-individual variation in different test populations. Annals of Clinical Biochemistry 198522 618-624. (doi:10.1177/000456328502200612)

32 Katzmarzyk PT, Janssen I, Ross R, Church TS \& Blair SN. The importance of waist circumference in the definition of metabolic syndrome: prospective analyses of mortality in men. Diabetes Care 200629 404-409. (doi:10.2337/diacare.29.02.06.dc05-1636)

33 Song Y, Manson JE, Meigs JB, Ridker PM, Buring JE \& Liu S. Comparison of usefulness of body mass index versus metabolic risk factors in predicting 10-year risk of cardiovascular events in women. American Journal of Cardiology 2007100 1654-1658. (doi:10.1016/j. amjcard.2007.06.073)

34 St-Pierre AC, Cantin B, Mauriège P, Bergeron J, Dagenais GR, Després JP \& Lamarche B. Insulin resistance syndrome, body mass index and the risk of ischemic heart disease. Canadian Medical Association Journal 2005172 1301-1305. (doi:10.1503/ cmaj.1040834)

35 Calori G, Lattuada G, Piemonti L, Garancini MP, Ragogna F, Villa M, Mannino S, Crosignani P, Bosi E, Luzi L et al. Prevalence, metabolic features, and prognosis of metabolically healthy obese Italian individuals: the Cremona Study. Diabetes Care 201134 210-215. (doi:10.2337/dc10-0665)

36 Ogorodnikova AD, Kim M, McGinn AP, Muntner P, Khan U \& Wildman RP. Incident cardiovascular disease events in metabolically benign obese individuals. Obesity 201220 651-659. (doi:10.1038/ oby.2011.243)

37 Flint AJ, Hu FB, Glynn RJ, Caspard H, Manson JE, Willett WC \& Rimm EB. Excess weight and the risk of incident coronary heart disease among men and women. Obesity 201018 377-383. (doi:10.1038/oby.2009.223)

Received 3 February 2016

Revised version received 14 April 2016

Accepted 26 May 2016 